Journal of Advanced Dielectrics

Vol. 2, No. 1 (2012) 1250002 (11 pages)

(C) World Scientific Publishing Company

DOI: 10.1142/S2010135X12500026

\title{
IMPEDANCE AND MODULUS SPECTROSCOPY CHARACTERIZATION OF SODIUM-BISMUTH TITANATE-BASED LEAD-FREE FERROELECTRIC MATERIALS
}

\author{
DHANANJAY K. SHARMA*, RAJU KUMAR*, RADHESHYAM RAI ${ }^{\dagger}$ *, \\ SEEMA SHARMA* and ANDREI L. KHOLKIN ${ }^{\dagger}$ \\ *Ferroelectric Research Laboratory, Department of Physics \\ A N College, Patna 800013, India \\ ${ }^{\dagger}$ Department of Ceramics and Glass Engineering and CICECO \\ University of Aveiro, 3810-193, Aveiro, Portugal \\ tradheshyamrai@ua.pt
}

Received 15 September 2011

Revised 11 October 2011

Published 27 February 2012

\begin{abstract}
In this paper, we present impedance spectroscopy of Sodium Bismuth Titanate-based materials belonging to $(1-x) \mathrm{Na}_{1 / 2} \mathrm{Bi}_{1 / 2} \mathrm{TiO}_{3}-x \mathrm{BaTiO}_{3}(x=0.04)(\mathrm{NBT}-\mathrm{BT})$ system. NBT-BT ceramics are prepared by high temperature solid-state reaction method. X-ray diffraction technique showed single-phase polycrystalline sample with an $\mathrm{ABO}_{3}$ perovskite structure. Dielectric behavior and the impedance relaxation were investigated in a wide range of temperature (room temperature $\left.(\mathrm{RT})-500^{\circ} \mathrm{C}\right)$ and frequency $(1 \mathrm{kHz}-1 \mathrm{MHz})$. A broad dielectric constant peak was observed over a wide temperature range around the phase transition temperature. The complex impedance plot exhibited one impedance semicircle identified over the frequency range of $1 \mathrm{kHz}-1 \mathrm{MHz}$, which is explained by the grain effect of the bulk. The centers of the impedance semicircles lie below the real axis, which indicates that the impedance response is a Cole-Cole type relaxation.
\end{abstract}

Keywords: Ceramics; X-ray diffraction; piezoelectricity perovskite; dielectric properties.

\section{Introduction}

Lead zirconate titanate (PZT)-based ceramics have been dominating piezoelectric and ferroelectric applications for more than half decades. However, the toxicity of $\mathrm{PbO}$ and its high vapor pressure during processing have stimulated an increasing demand for environment-friendly materials. Sodium potassium niboate $\mathrm{K}_{0.5} \mathrm{Na}_{0.5} \mathrm{NbO}_{3}(\mathrm{KNN})$, Sodium bismuth titanate $\left(\mathrm{Na}_{0.5} \mathrm{Bi}_{0.5} \mathrm{TiO}_{3}, \mathrm{NBT}\right)$ and its solutions

†Corresponding author. with other perovskites are considered to be good candidates to replace PZT-based ceramics. Sodium bismuth titanate (NBT) is a ferroelectric composition with an $\mathrm{ABO}_{3}$ perovskite structure of A-site complex occupation which is rich in phase transitions: Cubic paraelectric (PE), antiferroelectric (AFE) and ferroelectric (FE). ${ }^{1,2}$ Due to lead-free piezoceramics, i.e., $\left(\mathrm{K}_{0.5} \mathrm{Na}_{0.5}\right) \mathrm{NbO}_{3}$ (KNN)- and $\left(\mathrm{Bi}_{1 / 2} \mathrm{Na}_{1 / 2}\right) \mathrm{TiO}_{3}$ (BNT)-based materials, some 
research groups are largely focused on these materials for increasing demand on high performance piezoceramics, which are essential to realize the desired technological achievements e.g., energyeffective, miniaturized, and integrated. ${ }^{3}$ With a couple of breakthroughs, ${ }^{4,5}$ are now considered as the most promising in replacing lead-containing piezoceramics. ${ }^{3-6}$ Jo et al. ${ }^{7}$ reported that $\mathrm{CuO}$ as a sintering additive was utilized to explore a low-temperature sintering of lead-free piezoceramic which has shown a promise for actuator applications due to its large strain. Chaouchi et al. ${ }^{8}$ synthesized a $\mathrm{BaTiO}_{3}$-doped $\mathrm{Bi}_{0.5} \mathrm{Na}_{0.5} \mathrm{TiO}_{3}$ powders by a sol-gel method using acetate, nitrates and alkoxide as reactants. König et al. ${ }^{9}$ reported the influence of the synthesis conditions on the dielectric properties in the $\mathrm{Bi}_{0.5} \mathrm{Na}_{0.5} \mathrm{TiO}_{3}-\mathrm{KTaO}_{3}$ system. The cubic-tetragonal transition is indicated by a broad maximum in the dielectric spectrum that has been widely studied. ${ }^{10}$ However, because of its high coercive field, $E_{c}=73 \mathrm{kV} / \mathrm{cm}$, and relatively large conductivity, pure NBT is difficult to be poled so that its practical application is limited. These problems can be resolved by doping with different solid solutions as $\mathrm{BaTiO}_{3}(\mathrm{BT}), \mathrm{BiFeO}_{3}, \mathrm{NaNbO}_{3}$, $\mathrm{SrTiO}_{3},\left(\mathrm{~K}_{0.5} \mathrm{Bi}_{0.5}\right) \mathrm{TiO}_{3}$, etc. ${ }^{2,11-14}$ Among these solid solutions $(1-x) \mathrm{NBT}-(x) \mathrm{BT}$ system has attracted more attention due to the existence of a rhombohedral-tetragonal morphotropic phase boundary (MPB) near $x=0.06-0.08$. Many authors have attempted to enhance the electrical properties of NBT systems by doping of A-site and B-site with $\mathrm{La}^{3+}, \mathrm{Nb}^{5+}, \mathrm{Mn}^{2+}, \mathrm{Co}^{3+}$, etc. ${ }^{11,15-17}$ In general, in all ferroelectrics, the study of electrical conductivity is very important since the associated physical properties like piezoelectricity, pyroelectricity and also strategy for poling are dependent on the order and nature of conductivity in these materials. Compleximpedance diagrams have been found very useful to distinguish the contribution of resistivity from grain boundaries and the bulk of the material.

In view of the increased interest in NBT and doped NBT-based solid solutions, the present workers have undertaken a detailed study of electrical behavior in the temperature range from room temperature to $500^{\circ} \mathrm{C}$. AC impedance method is a very promising nondestructive testing method for analyzing ferroelectrics and piezoelectrics. In this paper we report the NBT-BT system synthesized by solid-state reaction method. The purpose of this study is to investigate with a special emphasis on the influence of BT on the structural, microstructure and various electrical properties of NBT-BT ceramics with nominal compositions of (0.96)\{ $\left.\mathrm{Na}_{1 / 2} \mathrm{Bi}_{1 / 2} \mathrm{TiO}_{3}\right\}-(0.04)\left\{\mathrm{BaTiO}_{3}\right\}$ ceramics.

\subsection{Theoretical background}

As we know, complex impedance spectroscopy (CIS) is a nondestructive method to study microstructure and electrical properties of solids. ${ }^{18}$ It enable us to evaluate the relaxation frequency $\left(\omega_{\max }\right)$ of the material. The relaxation frequency of the material, at a given temperature, is only an intrinsic property of the material independent of sample geometrical factors. Consequently, an analysis of the electrical properties (conductivity, dielectric constant/loss, etc.) carried out using relaxation frequency $\left(\omega_{\max }\right)$ gives unambiguous results when compared with those obtained at arbitrarily selected fixed frequencies. In this way, the impedance measurements enable us to eliminate the error, if any, due to stray frequency effects. These measurements on a material give us data having both resistive (real part) and reactive (imaginary part) components. It can be displayed conventionally in a complex plane plot (Nyquist diagram) in terms of the following parameters:

Complex impedance,

$$
Z^{*}(\omega)=Z^{\prime}-Z^{\prime \prime}=R s-j / \omega C s .
$$

Complex admittance,

$Y^{*}(\omega)=Y^{\prime}+Y^{\prime \prime}=1 / R p+j \omega C p=G(\omega)+j B(\omega)$.

Complex permittivity (dielectric constant),

$$
\varepsilon^{*}(\omega)=\varepsilon^{\prime}-j \varepsilon^{\prime \prime},
$$

where $R s, C s$ are the series resistance and capacitance; $R p, C p$ are the parallel resistance and capacitance.

So impedance analysis basically involves the display of the impedance data in different formalism and provides us the maximum possible information. The display of impedance data in the complex plane plot appears in the form of a succession of semicircles attributed to relaxation phenomena with different time constants due to the contribution of grain (bulk), grain boundary and interface/polarization in a polycrystalline material. Hence, the contribution to the overall electrical properties by various components in the material is separated out easily. In the case of a solid crystalline material, the physicochemico process and polarization events leading to 
the formation of double layer capacitors at the electrode material interface take place in such a way that this phenomenon can be represented in terms of equivalent circuit representations by a series combination of parallel RC units as shown in Fig. 3(b). The peak of the semicircle in the complex plane plot enables us to evaluate the relaxation frequency $\left(f_{\max }\right)$ of the bulk material using the relation,

$$
\begin{aligned}
\omega \tau_{\max } & =\omega_{\max } R_{b} C_{b}=1 \Rightarrow 2 \pi f_{\max } R_{b} C_{b}=1, \\
f_{\max } & =1 / 2 \pi R_{b} C_{b}, \\
\tau & =1 / 2 \pi f_{\max },
\end{aligned}
$$

where $R_{b}, C_{b}$ and $\tau$ refer to bulk resistance, bulk capacitance and relaxation time, respectively. The impedance data also enable us to investigate the information on relaxing dipoles in the material (dielectric relaxation spectroscopy) in terms of the real and imaginary parts of the complex dielectric constant

$$
\begin{gathered}
\varepsilon^{\prime}=\varepsilon^{\prime}-j \varepsilon^{\prime \prime} \text { as : } \\
\varepsilon^{\prime}=-Z^{\prime \prime} / \omega C_{0}\left(Z^{\prime 2}+Z^{\prime \prime 2}\right), \\
\varepsilon^{\prime \prime 2}=Z^{\prime} / \omega C_{0}\left(Z^{\prime 2}+Z^{\prime \prime 2}\right), \\
\tan \delta=Z^{\prime} / Z^{\prime \prime}=\varepsilon^{\prime \prime} / \varepsilon^{\prime}=M^{\prime \prime} / M^{\prime},
\end{gathered}
$$

where $Z^{\prime}, \varepsilon^{\prime}$ and $Z^{\prime \prime}$, $\varepsilon^{\prime \prime}$ are real and imaginary parts of impedance, dielectric constant and $\tan \delta$ is the dielectric loss factor, $\omega=2 \pi f$ is the angular frequency and $C_{0}=\varepsilon_{0} A / l=$ capacitance of the sample cell $(l=$ sample thickness, $A=$ sample area, $\varepsilon_{o}=$ vacuum permittivity, $\left.8.854 \times 10^{-12} \mathrm{~F} / \mathrm{m}\right)$.

\section{Experimental Details}

The conventional mixed oxide technique was used to prepare $0.96 \mathrm{Na}_{1 / 2} \mathrm{Bi}_{1 / 2} \mathrm{TiO}_{3}-0.04 \mathrm{BaTiO}_{3}(\mathrm{NBT}-4 \mathrm{BT})$ ceramics. The starting materials were high purity metal oxide or carbonate powders $\mathrm{Bi}_{2} \mathrm{O}_{3}(99.9 \%$, Aldrich Chem. Co), $\mathrm{Na}_{2} \mathrm{CO}_{3}$ (99.5\%, Aldrich Chem. Co), $\mathrm{BaCO}_{3}$ (99.9\%, Aldrich Chem. Co.) and $\mathrm{TiO}_{2}$ (99.9\%, Aldrich Chem. Co.). The carbonates were dried at $250^{\circ} \mathrm{C}$ for $6 \mathrm{~h}$ prior to use, then all the powders were weighed according to the required stoichiometry and mixed for $48 \mathrm{~h}$ using 2-propanol and zirconia media. The powders were calcined at $800^{\circ} \mathrm{C}$ for $2 \mathrm{~h}$. The powders were milled again for $12 \mathrm{~h}$. After drying powders were pressed into discs with diameter of $10 \mathrm{~mm}$ and thickness of $\approx 2 \mathrm{~mm}$. The compacted discs were sintered at $1020^{\circ} \mathrm{C}$ for $2 \mathrm{~h}$. Silver paste was fired on both sides of the samples at $200^{\circ} \mathrm{C}$ as electrodes. The XRD pattern was obtained, to identify the crystal phase of the samples, using an X-ray diffractometer (XRD-Philips Expert System) employing $\mathrm{CuK} \alpha$ radiation at $50 \mathrm{kV}$ and $40 \mathrm{~mA}$. The samples were scanned at an interval of $0.02^{\circ} / \mathrm{min}$ for $2 \theta$ in the range $10-80^{\circ}$. The identification of the peaks was carried out using the Topas 23 refinement programme. A scanning electron microscope (SEMLeica Stereoscan 440) was used to observe the microstructure of the sintered samples. The dielectric properties of the samples were determined at RT (room temperature) to $550^{\circ} \mathrm{C}$ using an impedance analyzer (PSM Impedance Analyser 1734) from $1 \mathrm{kHz}$ to $1 \mathrm{MHz}$.

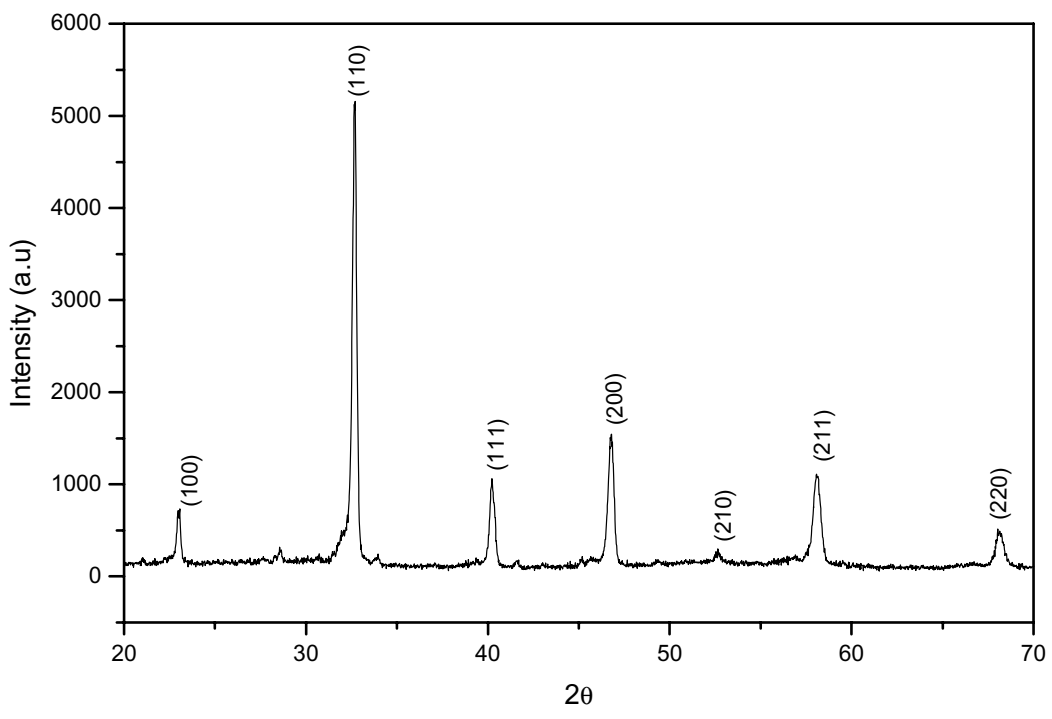

Fig. 1. Room temperature XRD pattern of NBT-4BT compound. 
Table 1. Lattice parameters $(\AA)$ and activation energies $E_{Z^{\prime \prime}}, E_{M^{\prime \prime}}$ calculated from $Z^{\prime \prime}$ and $M^{\prime \prime}$ plots for NBT-4BT system.

\begin{tabular}{cc}
\hline Properties & $x=0.04$ \\
\hline$a(\AA)$ & 5.2775 \\
$\alpha\left(^{\circ}\right)$ & 89.05 \\
$E_{Z^{\prime \prime}}$ & 1.75 \\
$E_{M^{\prime \prime}}$ & 1.51 \\
$\varepsilon^{\prime}$ at $R T$ & 979 \\
$\varepsilon^{\prime}$ at $T_{\mathrm{c}}$ & 2030 \\
$\tan \delta_{R T}$ & 0.176 \\
$\tan \delta_{T c}$ & 0.048 \\
$T_{\mathrm{c}}\left({ }^{\circ} \mathrm{C}\right)$ & 320 \\
Density $($ experimental $)\left(\mathrm{g} / \mathrm{cm}^{3}\right)$ & 5.006 \\
Density (theoretical) $\left(\mathrm{g} / \mathrm{cm}^{3}\right)$ & 5.65 \\
\hline
\end{tabular}

\section{Results and Discussion}

Figure 1 shows the X-ray diffraction patterns of NBT-4BT ceramics. The spectra examined are single phase with perovskite type structure together with a tiny amount of intermediate phase, attributed to a $\mathrm{Bi}_{3} \mathrm{Ti}_{4} \mathrm{O}_{12}$ compound. At room temperature, the symmetry of NBT is rhombohedral and $\mathrm{BaTiO}_{3}$ is tetragonal. Our solid solutions have rhombohedral morphotropic phase boundary. The room temperature lattice parameters are calculated and tabulated in Table 1. This table also gives the theoretical and experimental densities. All the samples prepared have about $95 \%$ of theoretical density.

Figure 2 exhibits the microstructure (SEM) of the sample. The grain size in the samples is of the order of $1-3 \mu \mathrm{m}$. The fracture surfaces show homogeneous grains and dense structure which is in good agreement with the density $\left(5.65 \mathrm{gm} / \mathrm{cm}^{3}\right)$, determined experimentally by Archimedes method.

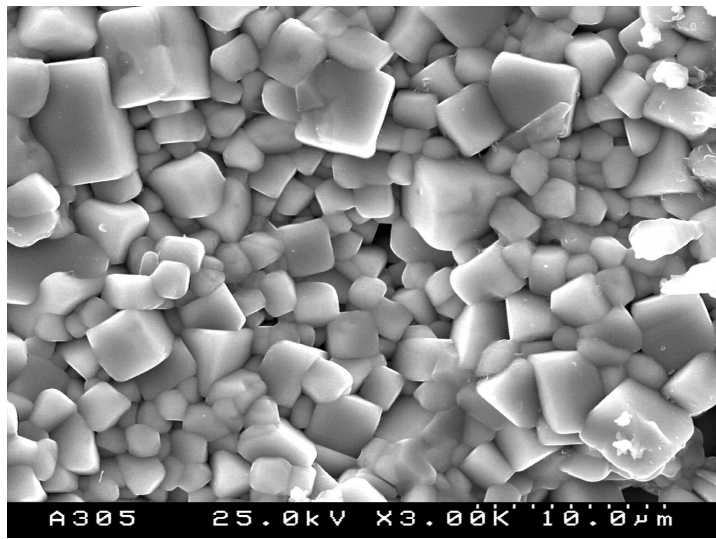

Fig. 2. SEM graph of NBT-4BT compound.
Figure 3(a) shows the dielectric properties of NBT-4BT samples at different frequencies with temperature. The dielectric constant at room temperature and dielectric maxima of the ceramics decrease with increasing frequency. The dielectric loss at different frequencies of the sintered samples is shown in Fig. 3(b). Most of the works cited in literature have shown that the system presents a MPB $\sim 7 \mathrm{~mol} \%$ BT, all the materials across the full

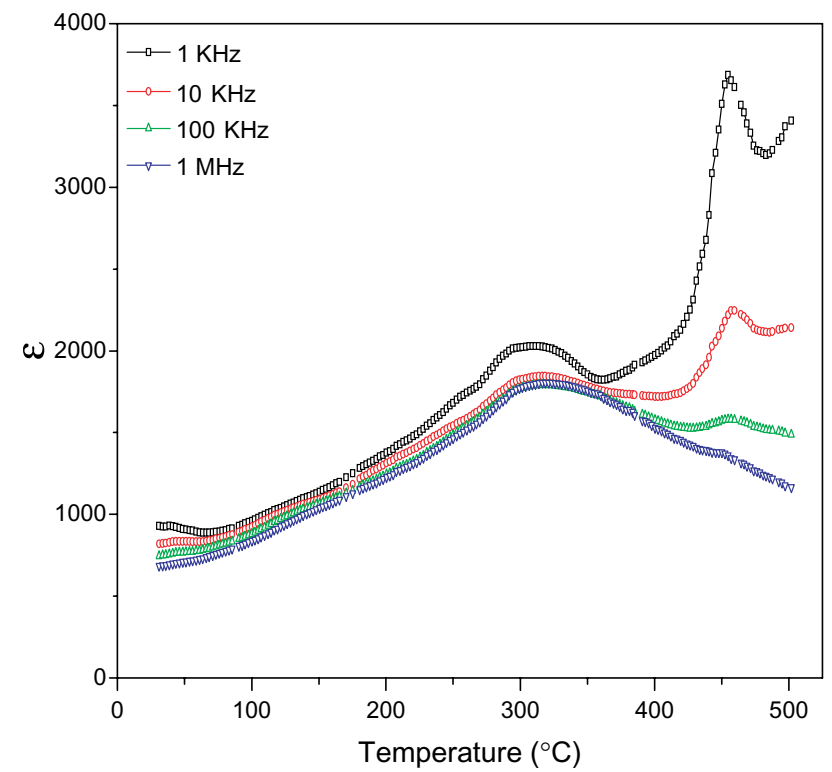

(a)

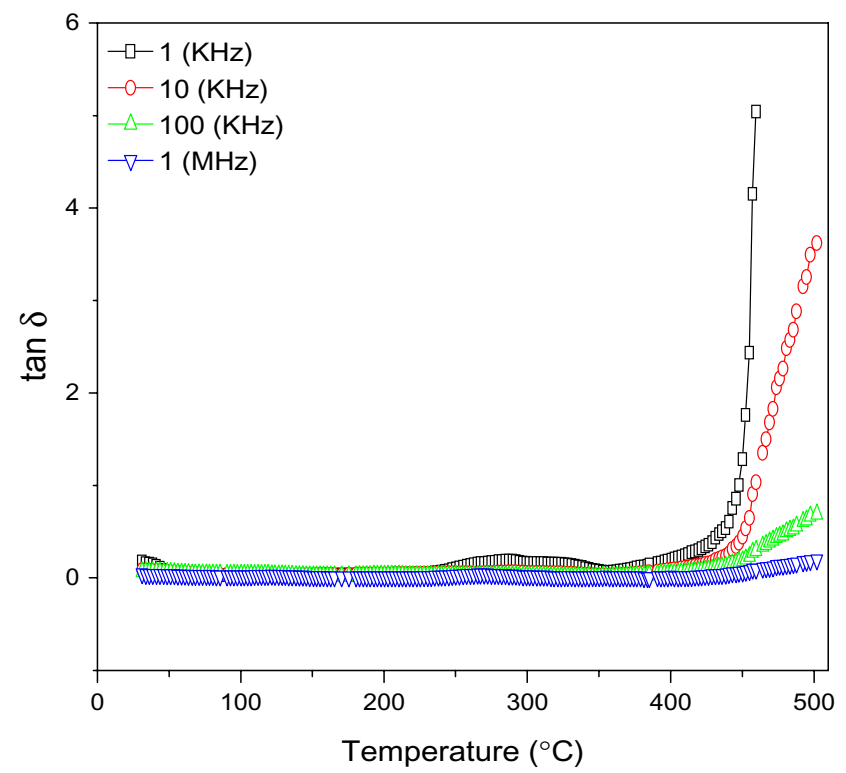

(b)

Fig. 3. (Color online) (a) Variation of dielectric constant with temperature, (b) Variation of loss $(\tan \delta)$ with temperature at various frequencies, respectively. 


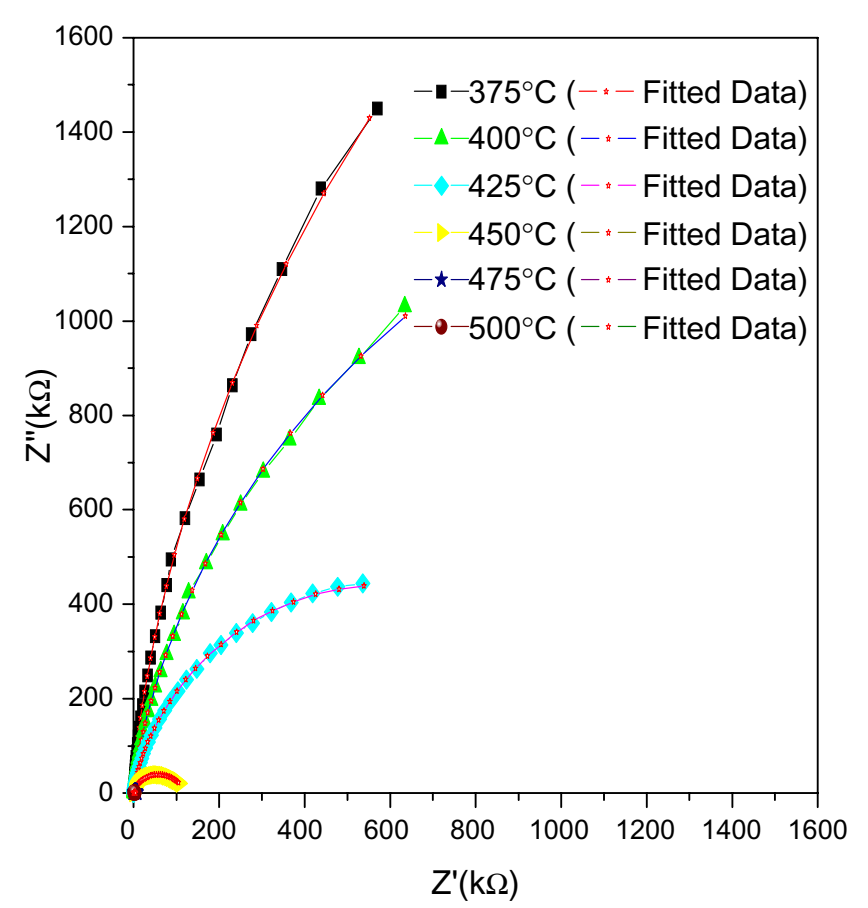

(a)

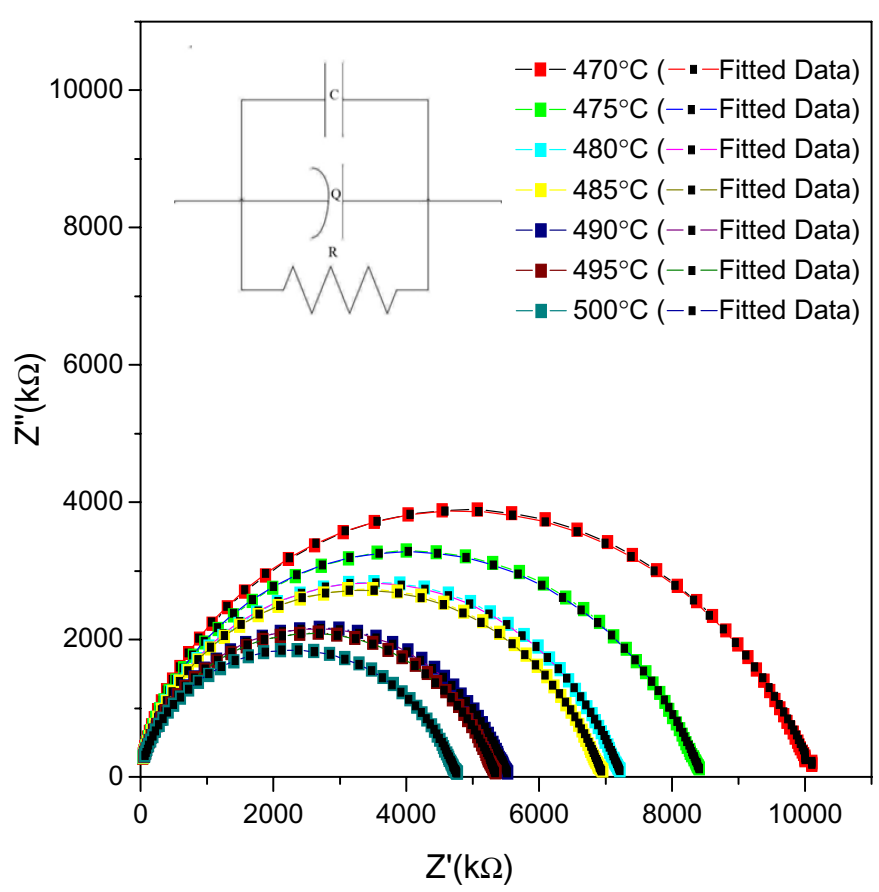

(b)

Fig. 4. (Color online) Variation of real and imaginary part of impedance with temperature of NBT-4BT compound.

composition range being ferroelectric at room temperature. The dielectric constant tends to peak around $T_{\mathrm{m}} \sim 310^{\circ} \mathrm{C}$ at $100 \mathrm{kHz}$. At higher frequencies the peak is near to $320^{\circ} \mathrm{C}$. The loss also depicts the peak around the same temperature $\left(310^{\circ} \mathrm{C}\right)$. It is obvious that there exist ferroelectric and paraelectric phases in different temperature ranges, which are in good agreement with those reported by some authors. ${ }^{19,20} T_{\mathrm{d}} \sim 450^{\circ} \mathrm{C}$ refers to the transition temperature between ferroelectric phase and antiferroelectric phase and $T_{\mathrm{m}}$ represents the temperature at which the dielectric constant $\varepsilon_{\mathrm{r}}$ reaches the maximum. It can be seen that both $\varepsilon$ and $\tan \delta$ are strongly frequency dependent near $T_{\mathrm{d}}$. At $T_{\mathrm{m}}$, the ceramics exhibit a diffuse phase transition behavior. These indicate that NBT-BT ceramics are diffuse type, which could be associated with the complex occupation of $\mathrm{Ba}^{2+}, \mathrm{Na}^{+}$and $\mathrm{Bi}^{3+}$ cations at $\mathrm{A}$-sites. The maximum of the permittivity decreases as the measurement frequency increases and its temperature is shifted towards high temperatures as well which is typical relaxor behavior present in the ferroelectric systems.

The electrical properties of the materials have been investigated using complex impedance spectroscopy (CIS). It is an important tool to analyze the electrical properties of a polycrystalline material in view of its capability of correlating the sample electrical behavior to its microstructure.

Figure 4 show temperature-dependent spectra (Nyquist plot) of NBT-4BT material. The impedance spectrum is featured by semicircular arcs. The nature of variation of the arcs with temperature and frequency provides various clues of the materials. The impedance spectra are characterized by the appearance of a single semicircular arc and the intercept of the semicircular arc with the real axis $\left(Z^{\prime}\right)$ gives us an estimate of the bulk resistance $\left(R_{b}\right)$ of the material. It has been observed that the bulk resistance of the material decreases with increase in temperature showing a typical semiconducting property, i.e., negative temperature coefficient of resistance (NTCR) behavior.

It is observed that with the increase in temperature the slope of the lines decrease and the lines bend towards real $\left(Z^{\prime}\right)$ axis and at $450^{\circ} \mathrm{C}$; a semicircle could be traced, indicating the increase in conductivity of the sample. It can also be observed that the peak maxima of the plots decrease and the frequency for the maximum shifts to higher values with the increase in temperature. It can be noticed that the complex impedance plots are not represented by full semicircle, rather the semicircular arc is depressed and the center of the arc lies below the real $\left(Z^{\prime}\right)$ axis 


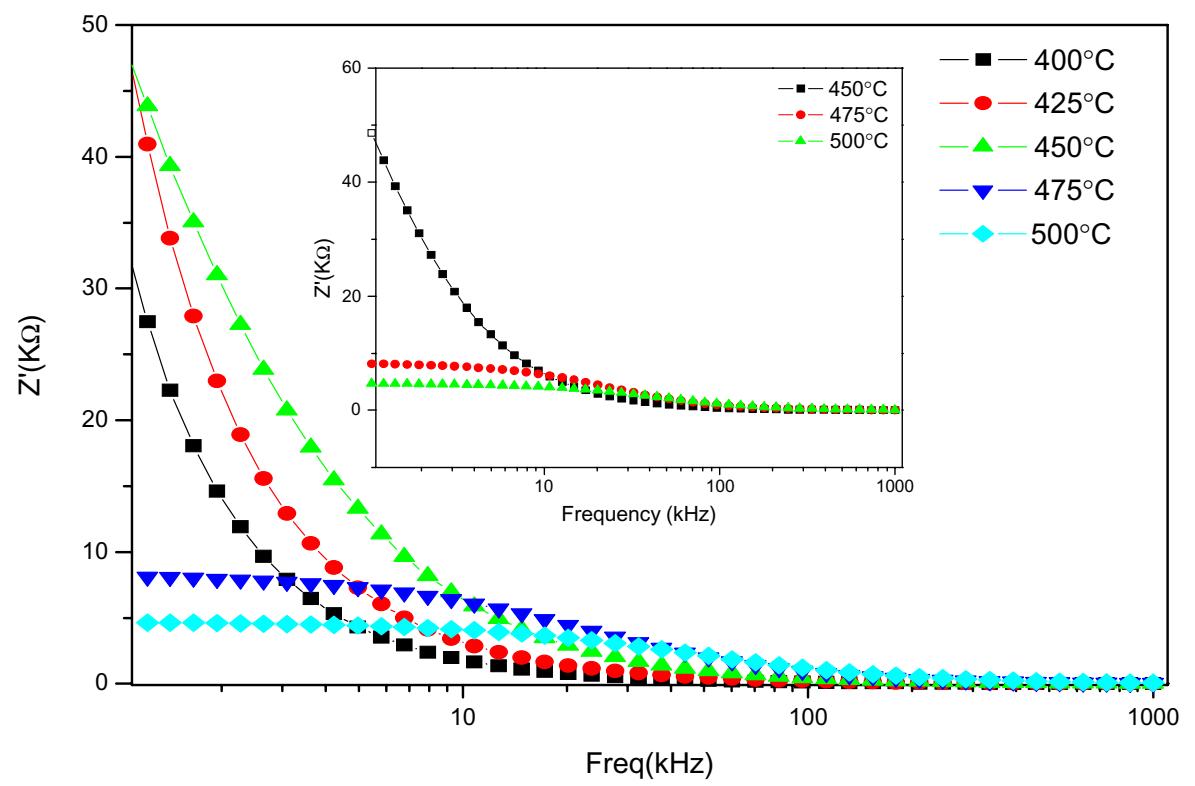

Fig. 5. (Color online) Variation of real part of impedance with frequency of NBT-4BT compound.

suggesting the relaxation to be of polydispersive non-Debye type in samples. This may be due to the presence of distributed elements in the material electrode system. ${ }^{21,22}$ The correlation among the Debye relaxors may start developing via formation of nanopolar clusters of $\mathrm{Na}-\mathrm{TiO}_{3}$ and $\mathrm{Bi}-\mathrm{TiO}_{3} \cdot{ }^{23,24}$ Since the relaxation times of the relaxors within polar clusters are distributed over a wide spectrum at higher temperatures, their response to external field is in a different time domain. This results in the deviation from Cole-Cole plots. It is clear from Fig. 4 that with the increase of measuring temperature Cole-Cole plots become stretched and/or splitted into two discrete semicircles, inferring the possible average profile of various Cole-Cole semicircles. The split as well as stretched semicircles may be due to secondary elements like interfacial capacitance or defects. According to Debye's model, a material having single relaxation time gives rise to an ideal semicircle centered on the real axis. The first semicircle (at higher frequencies) attributed to transport phenomena in the bulk and another at lower frequencies, is related to transport phenomena at grain boundary. ${ }^{25,26}$ An equivalent circuit is being used to provide a complete picture of the system and establish the structural property relationship of the materials. Comparison of complex impedance plots (symbols) with fitted data (lines) using commercially available software $\mathrm{Z}_{\text {Simp }}$ WIN Version 2 has been given in the figure. To model the non-Debye response, constant phase element $(\mathrm{CPE})$ is used in addition to resistors and capacitors. Here it has also been clearly observed from the Nyquist plots that the influence of grain size on the inter grain resistivity increases with decreasing grain size.

Figure 5 present the real part of impedance $\left(Z^{\prime}\right)$ as a function of frequency. $Z^{\prime}$ has higher values at lower frequencies and decreases up to $100 \mathrm{kHz}$ and attains a constant value beyond that. Figure 6 present the variation of imaginary part of impedance $\left(Z^{\prime \prime}\right)$ as a function of frequency at different set of temperatures. With the increase of frequency, the real part of impedance $\left(Z^{\prime}\right)$ and imaginary part of impedance $\left(Z^{\prime \prime}\right)$ decreases with increase of frequency. At higher frequency side all the curves merge. As the temperature increases, the peak in $Z^{\prime \prime}$ versus frequency curve appears. The peak shifts towards higher frequency side with increasing temperature showing that the resistance of the bulk material is decreasing. Also, the magnitude of $Z^{\prime \prime}$ decreases with increasing frequency. This would imply that dielectric relaxation is temperature dependent, and there is apparently not a single relaxation time. It is evident that with increasing temperature, there is broadening of the peaks and at higher temperatures, the curves appear almost flat.

Figure 7 shows the variation of real part of modulus as a function of frequency at different temperatures. The variation of $M^{\prime}$ with frequency for NBT-4BT samples shows a dispersion tending towards $M_{\infty}$ (the asymptotic value of $M^{\prime}$ at higher frequencies) and it (dispersion) shifts towards 


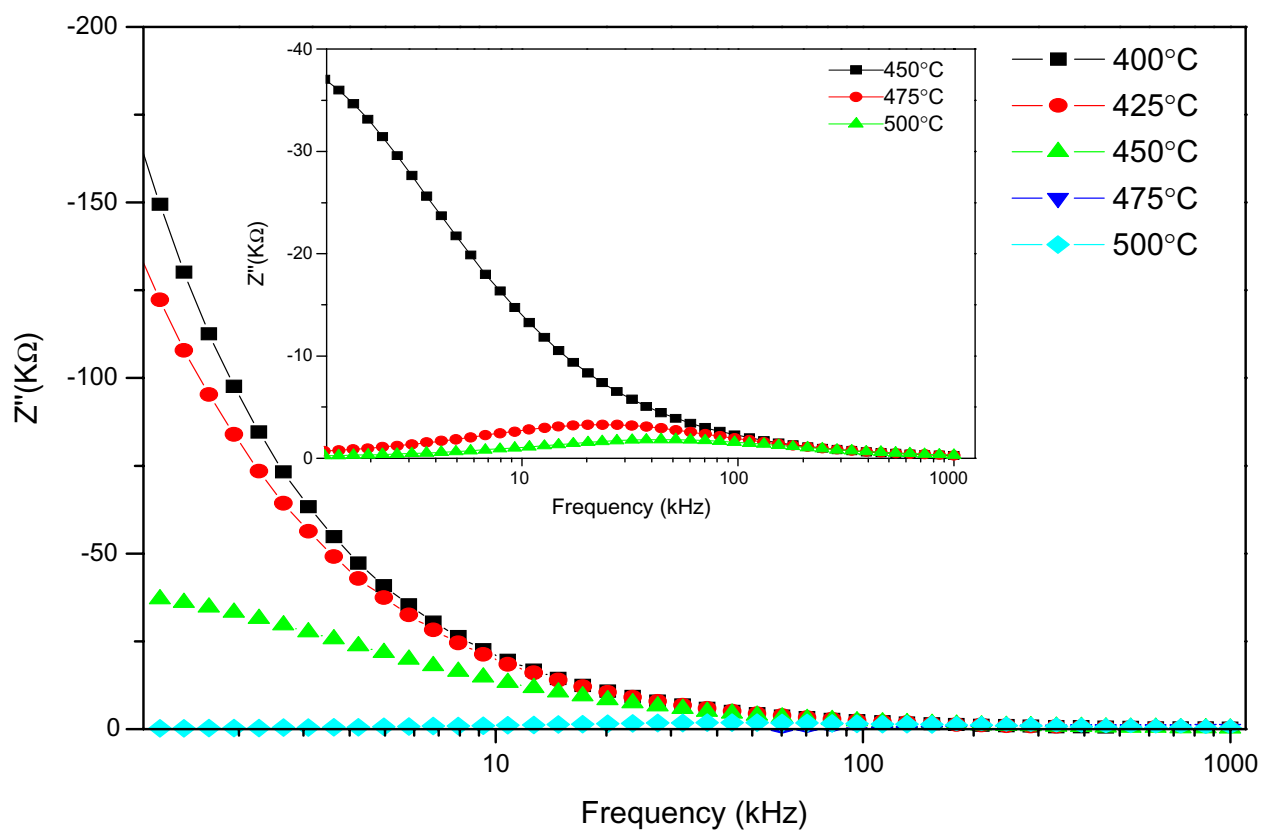

Fig. 6. (Color online) Variation of imaginary part $\left(Z^{\prime \prime}\right)$ of impedance with frequency of NBT-4BT compound.

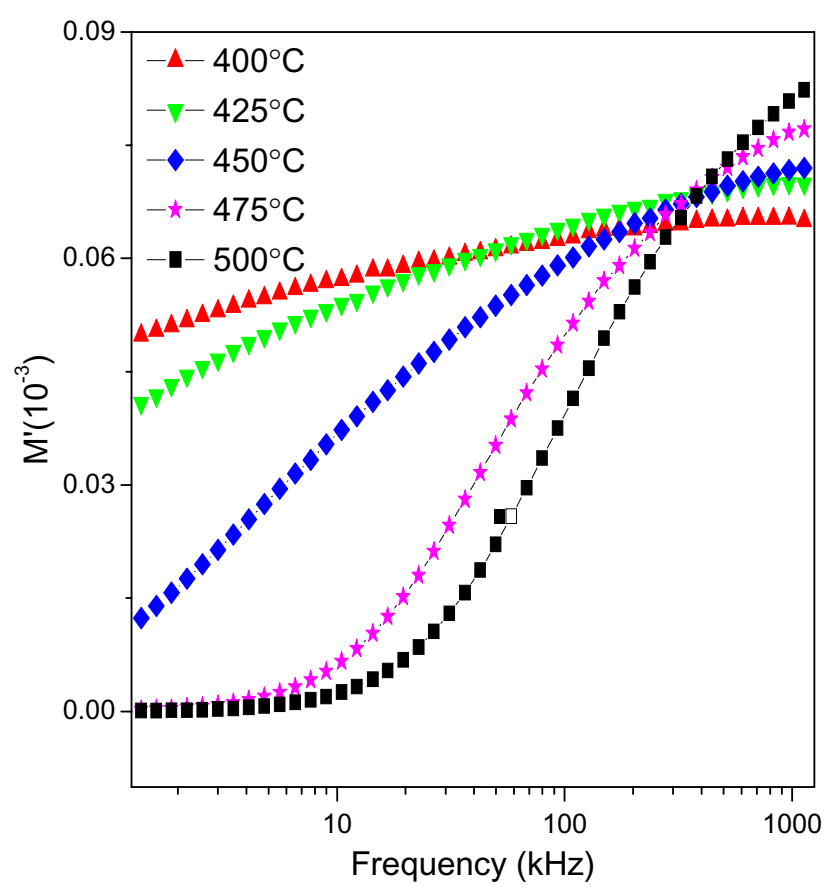

(a)

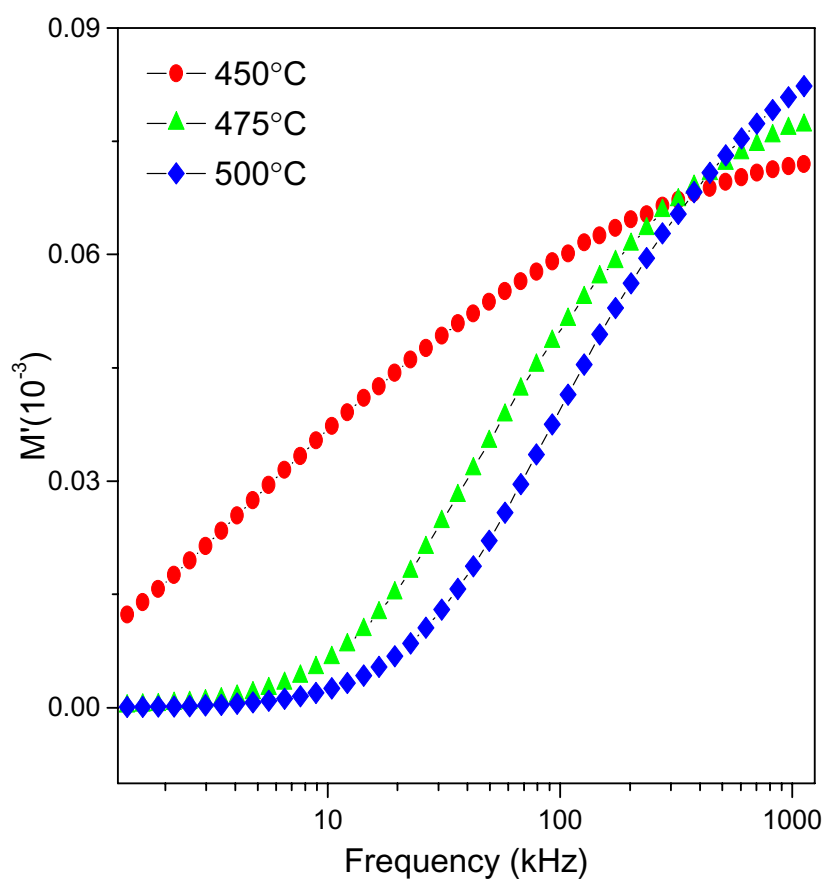

(b)

Fig. 7. (Color online) Variation of real part of modulus $\left(M^{\prime}\right)$ with frequency of NBT-4BT compound.

higher frequency side as temperature increases. Monotonous dispersion on increasing frequency at lower temperatures may be caused by short range mobility of charge carriers. Such results may possibly be related to a lack of restoring force governing the mobility of the charge carriers under the action of an induced electric field. The value of $M^{\prime}$ decreases with rise in temperature in the observed frequency range. Figure 8 depict variation of imaginary part of modulus $\left(M^{\prime \prime}\right)$ with frequency. The peaks are asymmetric and broader than the ideal Debye curve. The frequency range where the peaks 


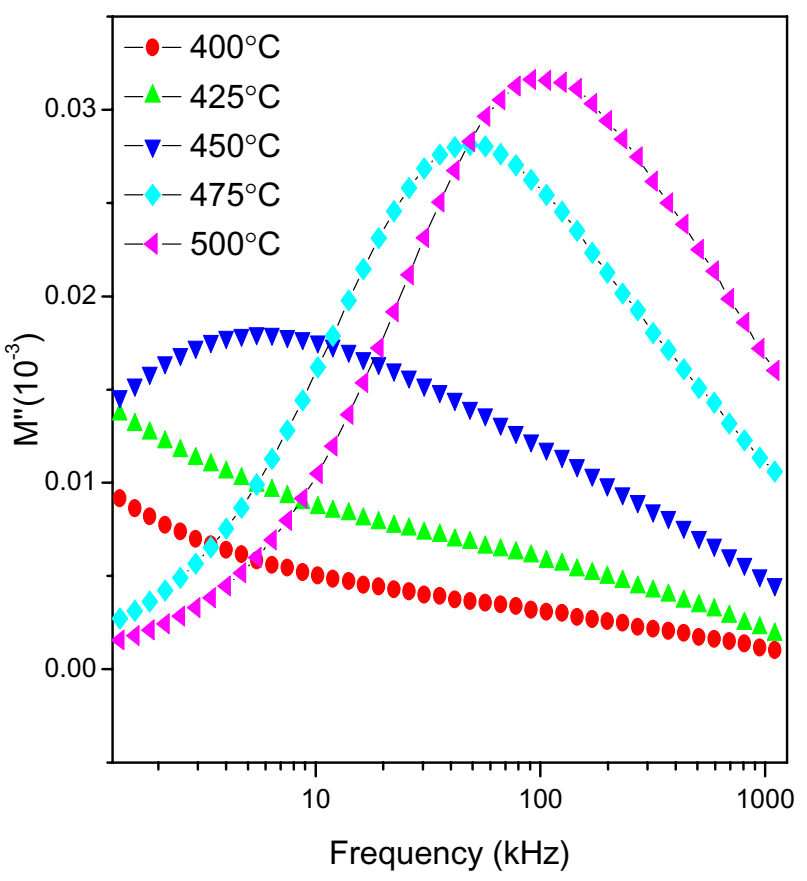

(a)

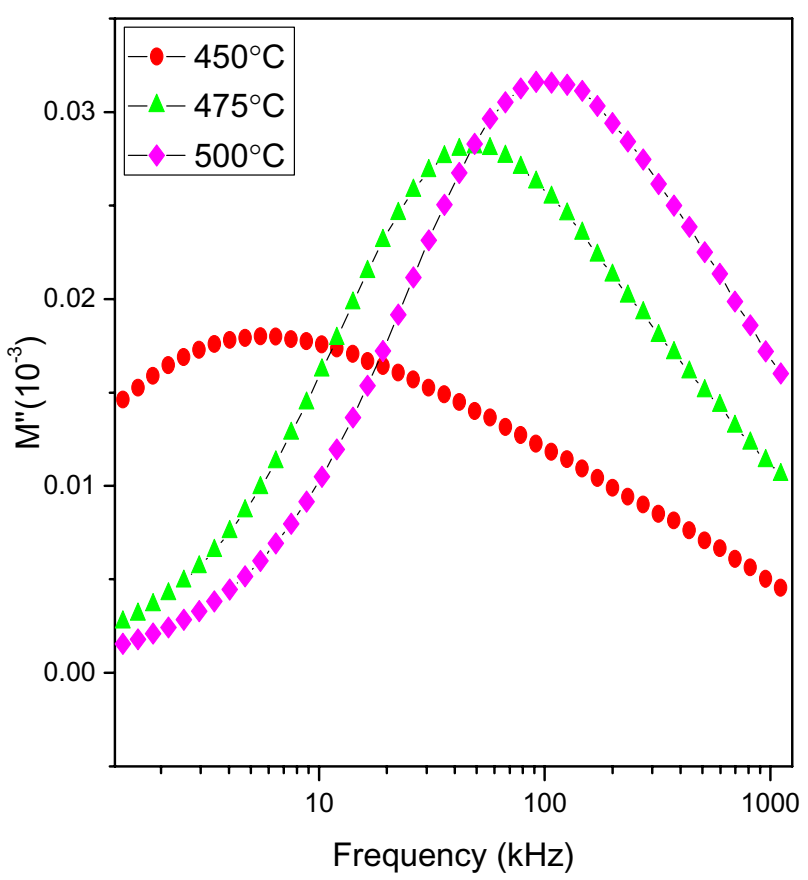

(b)

Fig. 8. (Color online) Variation of imaginary part of modulus $\left(M^{\prime \prime}\right)$ with frequency of NBT-4BT compound.

occur is the indicative of transition from long range to short range mobility. ${ }^{26,27}$ The asymmetric plot of $M^{\prime}$ is because of the stretched exponential character of relaxation time of the material.

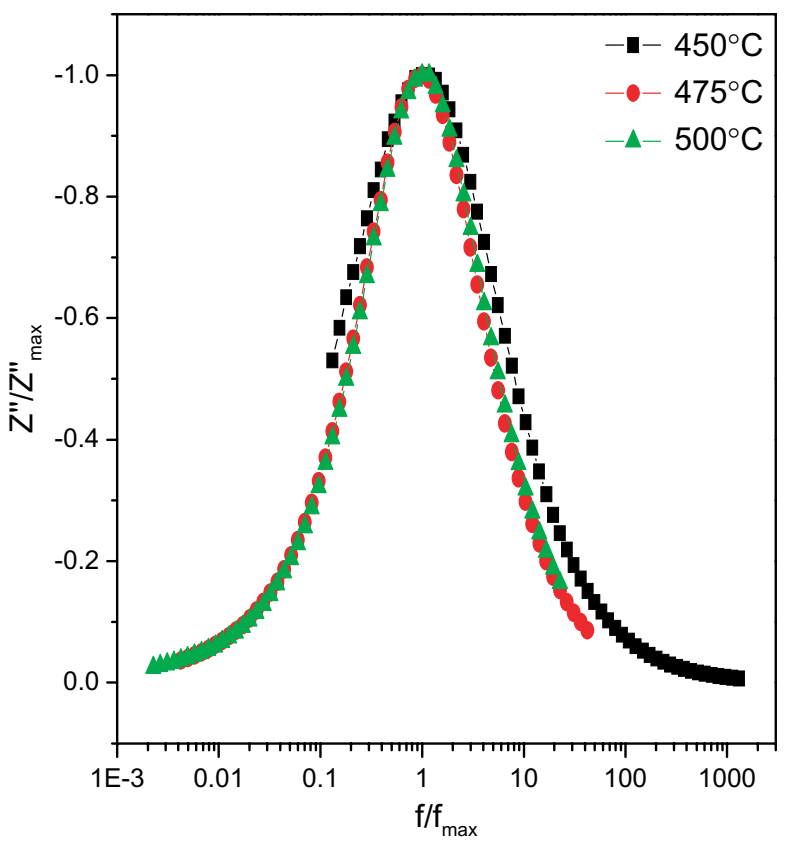

(a)
Figures 9 (a) and 9(b) shows the normalized plot of $Z^{\prime \prime} / Z_{\max }^{\prime \prime}$ and $M^{\prime \prime} / M_{\max }^{\prime \prime}$ versus $\log \left(f / f_{\max }\right)$ (master modulus curve) at different temperatures. The normalized plot overlaps on a single master

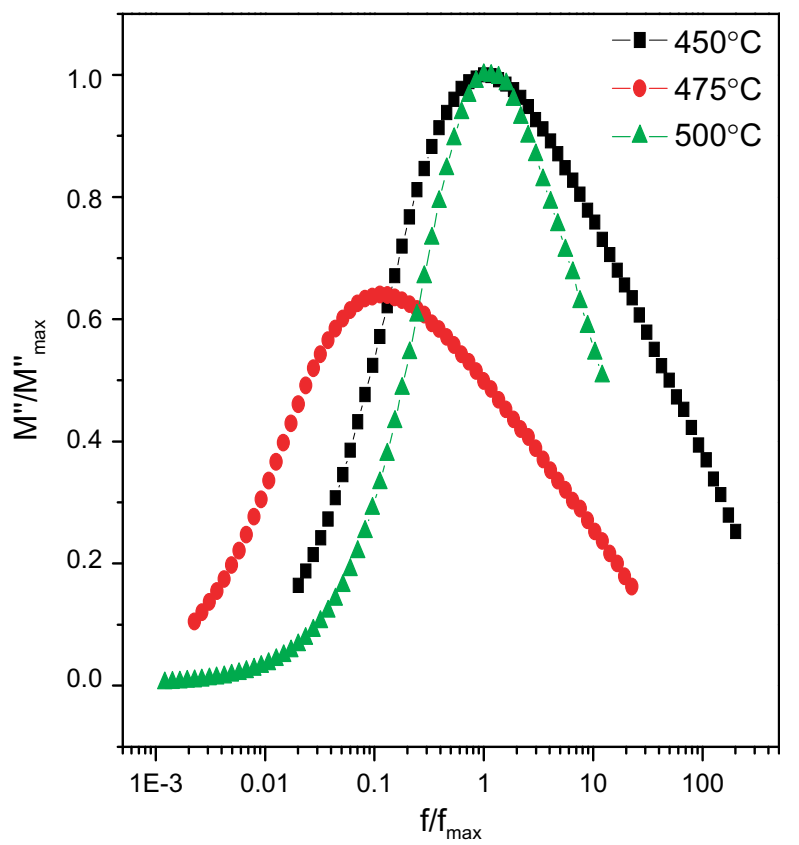

(b)

Fig. 9. (Color online) (a) Impedance and (b) Modulus scaling behavior of compounds in the master curves of NBT-4BT compound, respectively. 


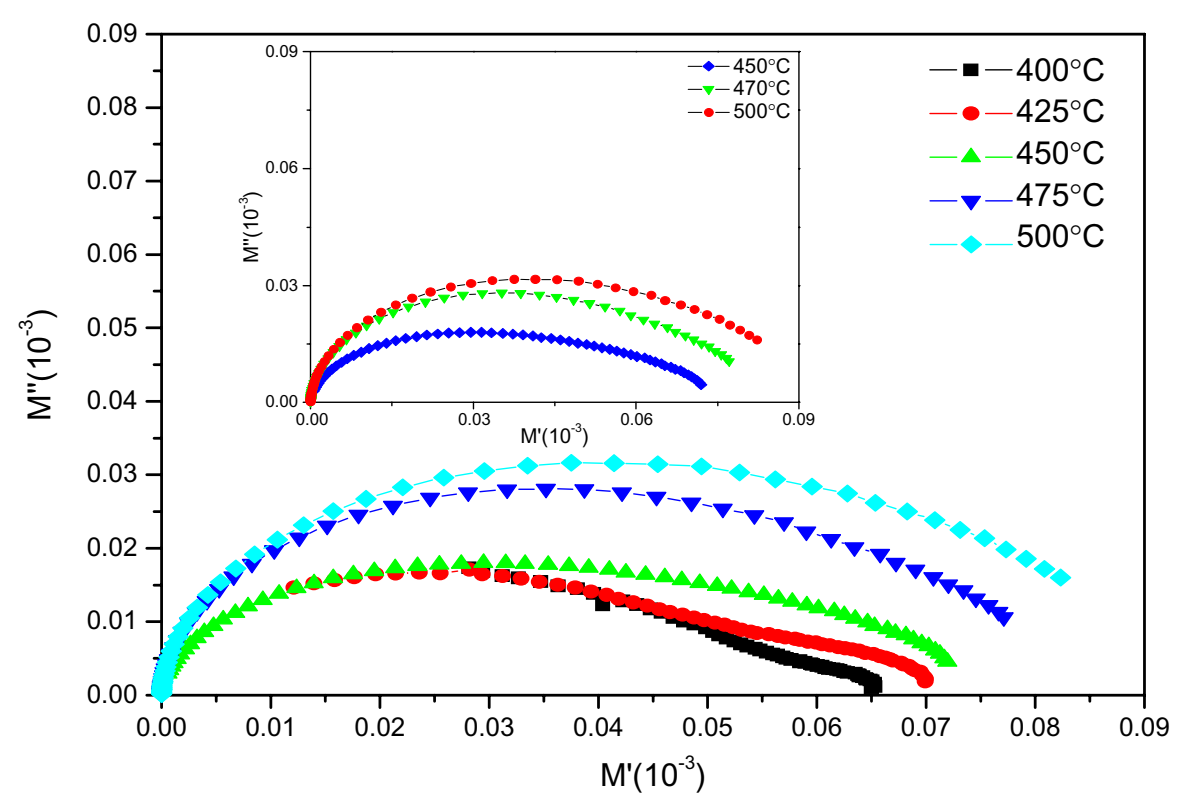

Fig. 10. (Color online) Variation of real and imaginary part of modulus with temperature of NBT-4BT compound.

curve at different temperatures (i.e., same shape and pattern in the peak position with slight variation in full width at half maximum FWHM with rise in temperature). Thus the dielectric processes occurring in the material can be investigated via master modulus plot. ${ }^{28}$ The value of FWHM evaluated from the normalized spectrum is greater than $\log \frac{2+\sqrt{3}}{2-\sqrt{3}}$, and this indicates about non-Debye type

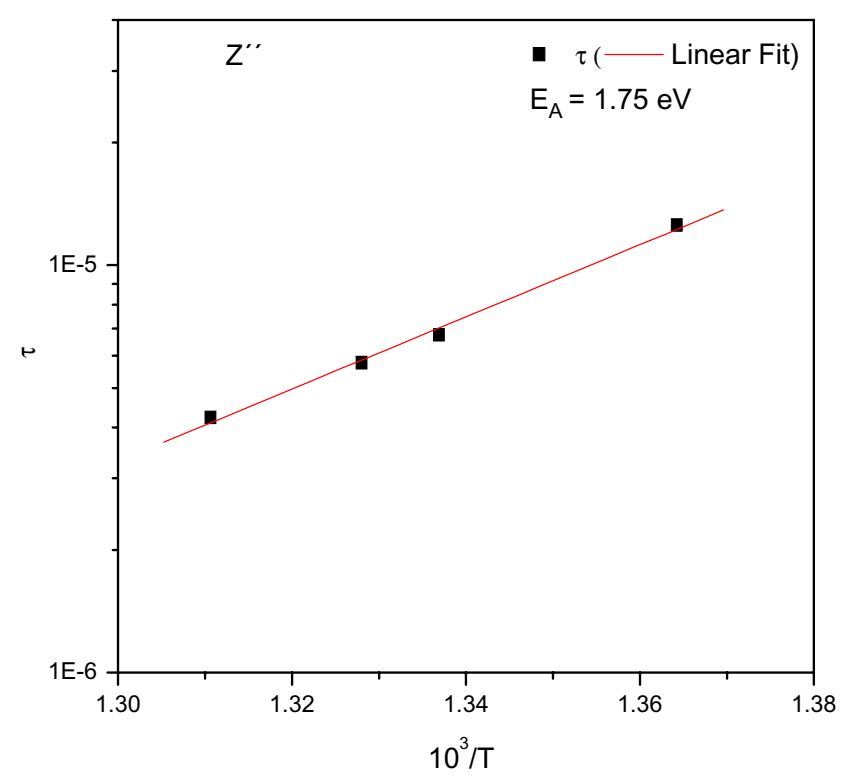

(a) behavior which is well supported by complex modulus plot.

Figure 10 shows the complex electric modulus graph of sample at different temperatures. The patterns are characterized by the presence of little asymmetric and depressed semicircular arcs whose center does not lie on $M^{\prime}$ axis. The behavior of electric modulus spectrum is suggestive of the

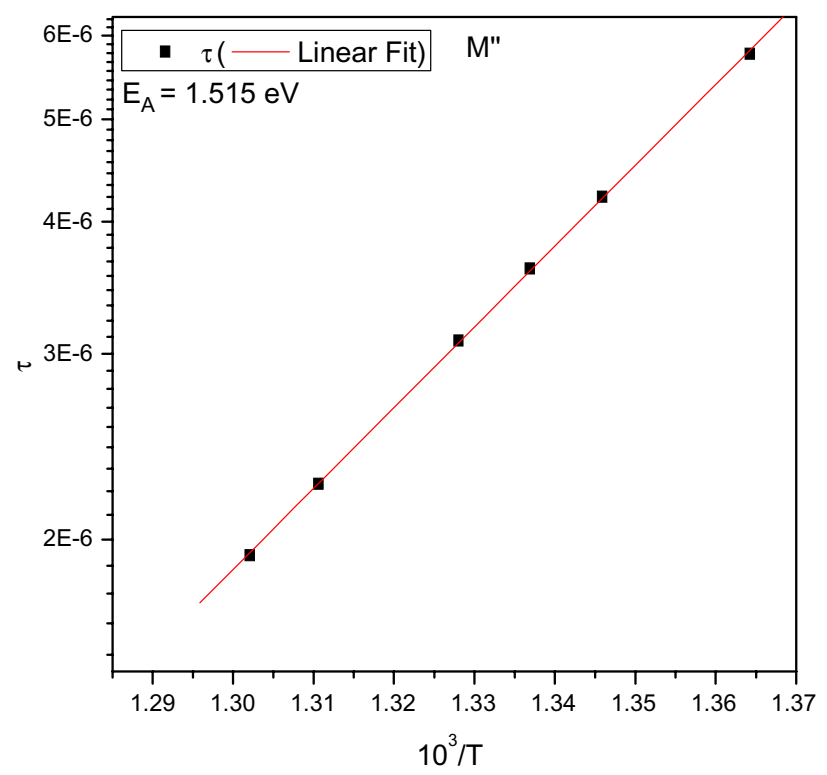

(b)

Fig. 11. (Color online) Variation of relaxation time with inverse of temperature for (a) $Z^{\prime \prime}$ and (b) $M^{\prime \prime}$ of NBT-4BT compound. 
temperature-dependent hopping type of mechanism for electric conduction (charge transport) in the system and non-Debye type dielectric relaxation.

In a relaxation system, one can determine the probable relaxation time $(\tau)$ from the position of the loss peak in the $Z^{\prime \prime}$ as well as $M^{\prime \prime}$ versus $\log f$ plots according to the relation: $\tau=1 / \omega=1 / 2 \pi \phi,(f$ is the relaxation frequency). The nature of variation of $\tau$ with temperature of compounds for impedance and modulus plots has been shown in Figs. 11(a) and 11(b). All the curves find to follow the Arrehenius relation: $\tau=\tau_{0} \exp \left(E_{\mathrm{a}} / k T\right)$ where $\tau_{\mathrm{o}}$ is preexponential factor, $E_{\mathrm{a}}$ is the activation energy, $k$ is Boltzmaan constant and $T$ is the absolute temperature. The semiconducting nature of the grains in ceramics is believed to be due to the loss of oxygen during high temperature sintering process. The $\tau$-value of the NBT-4BT compound was found to be decreasing on increasing temperature, which is a typical behavior of a semiconductor. The values of activation energy calculated from the slope of $\log (\tau)$ versus $10^{3} / T$ are given in Table 1 . Generally the activation energy calculated using $Z^{\prime \prime}$ spectra $E_{Z \prime \prime}$ represents the localized conduction and those calculated from $M^{\prime \prime}$ spectrum $E_{M^{\prime \prime}}$ represents nonlocalized conduction (i.e., long range conductivity).

Figure 12 compares the frequency-dependent behavior of $M^{\prime \prime}$ with that of $Z^{\prime \prime}$ for the sample at high temperature $\left(500^{\circ} \mathrm{C}\right)$. It is found that there is a wide gap between $M^{\prime \prime}$ and $Z^{\prime \prime}$ peaks showing the departure from Debye type of behaviors. The $Z^{\prime \prime}$ peaks are asymmetric at lower frequency side while $M^{\prime \prime}$ peak are asymmetric on the higher frequency side. In the entire range of observed temperature no overlapping temperature could be found, indicating

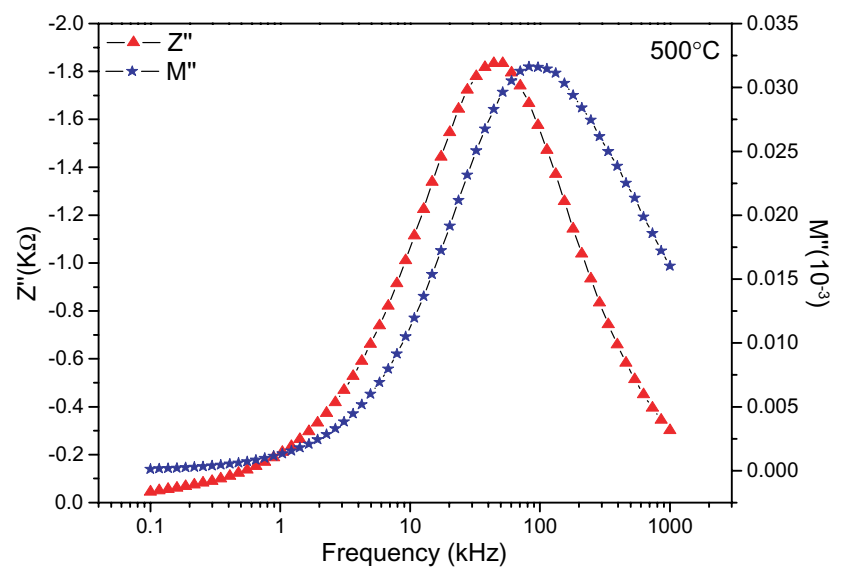

Fig. 12. (Color online) Variation of $Z^{\prime \prime}$ and $M^{\prime \prime}$ with frequency at $\left(500^{\circ} \mathrm{C}\right)$ temperature of NBT-4BT compound. that the samples have component both from long range conductivity and localized relaxation.

\section{Conclusion}

NBT-4BT ceramics have been fabricated by solid-state reaction technique and its structure, dielectric, ferroelectric and impedance properties have been studied systematically. The results of XRD measurement reveal that BT has diffused into the NBT lattice to form a solid solution in singlephase perovskite structure. The ceramics have a dense fine microstructure when sintered at $1020^{\circ} \mathrm{C}$ for $2 \mathrm{~h}$. Impedance analyzes indicated the presence of grain effect in NBT-BT samples. Sample showed dielectric relaxation, which is found to be of nonDebye type and the relaxation frequency shifted to higher side with the increase of temperature. The Nyquist plot and conductivity studies showed the NTCR character of samples. Further, the conductivity at different temperatures indicated that the conduction process is thermally activated process.

\section{References}

1. X. Y. Zhou, H. S. Gu, T. Y. Wang, W. Y. Li and T. S. Zhou, Mater. Lett. 59, 1649 (2005).

2. S. E. Park and K. S. Hong, J. Appl. Phys. 79, 383 (1996).

3. J. Rödel, A. B. N. Kounga, M. W. Eibl, D. Koch, A. Bierwisch, W. Rossner, M. J. Hoffmann, R. Danzer and G. Schneider, J. Eur. Ceram. Soc. 29, 1549 (2009).

4. T. Takenaka, K. Maruyama and K. Sakata, Jpn. J. Appl. Phys. 30, 2236 (1991).

5. Y. Saito, H. Takao, T. Tani, T. Nonoyama, K. Takatori, T. Homma, T. Nagaya and M. Nakamura, Nature 432, 84 (2004).

6. P. K. Panda, J. Mater. Sci. 44, 5049 (2009).

7. W. Jo, J. B. Ollagnier, J. L. Park, E. M. Anton, O.-J. Kwon, C. Park, H. H. Seo, J. S. Lee, E. Erdem, R. A. Eichel and J. Rödel, J. Eur. Ceram. Soc. 31, 2107 (2011).

8. A. Chaouchi, S. Kennour, S. d'Astorgb, M. Rguitib, C. Courtoisb, S. Marinel and M. Aliouat, J. Alloy. Compd. 509, 9138 (2011).

9. J. König, M. Spreitzer and D. Suvorov, J. Eur. Ceram. Soc. 31, 1987 (2011).

10. M. Raghavender, G. S. Kumar and G. Prasad, Pramana 72, 999 (2009).

11. E. Dul'kin, E. Mojaev, M. Roth, S. Greicius and T. Granzow, Appl. Phys. Lett. 92, 012904 (2008). 
12. Y. Li, W. Chen, J. Zhou, Q. Xu, H. Sun and R. Xu, Mater. Sci. Eng. B 112, 5 (2004).

13. Y. M. Li, W. Chen, J. Zhou, Q. Xu, X. Gu and R. H. Liao, Phys. B: Condens. Matter 365, 76 (2005).

14. H. Ishii, H. Nagata and T. Takenaka, Jpn. J. Appl. Phys. 40, 5660 (2001).

15. K. N. Singh and P. K. Bajpai, J. Alloy. Compd. 509, 5070 (2011).

16. C. Xu, D. Lin and K. W. Kwok, Solid State Sci. 10, 934 (2008).

17. D. Lin, C. Xu, Q. Zheng, Y. Wei and D. Gao, J. Mater. Sci. Mater. Electron. 20, 393 (2009).

18. B. Tiwari and R. N. P. Choudhary, J. Alloy. Compd. 493, 1 (2010).

19. T. Takenaka, K. Maruyama and K. Sakata, Jpn. J. Appl. Phys. 30, 2236 (1991).

20. R. Z. Zuo, C. Ye, X. S. Fang and J. W. Li, J. Eur. Ceram. Soc. 28, 871 (2008).
21. J. R. Mac Donald (ed.), Impedance Spectroscopy Emphasizing Solid Materials and Systems (Wiley, New York, 1987).

22. K. S. Rao, B. Tilak, K. C. V. Rajulu, A. Swathi and H. Workineh, J. Alloy. Compd. 509, 7121 (2011).

23. K. Prasad, K. Kumari, K. P. Chandra, K. L. Yadav and S. Sen, Mater. Sci. 27, 2 (2009).

24. P. Bonneau, O. Garnier, G. Calvarin, E. Husson, J. R. Gavarri, A. W. Hewat and A. Morrel, J. Solid State Chem. 91, 350 (1991).

25. S. Zha, C. Xia and G. Meng, J. Power Sources 115, 44 (2003).

26. A. Shukla and R. N. P. Choudhary, Phys. B: Condens. Matter 406, 2492 (2011).

27. A. Shukla, R. N. P. Choudhary and A. K. Thakur, J. Phys. Chem. Solids 70, 1401 (2009).

28. A. Shukla, R. N. P. Choudhary and A. K. Thakur, J. Mater. Sci.: Mater. Electron. 20, 745 (2009). 